\title{
PERFIL SOCIOECONÔMICO DOS TITULARES DE AGROINDÚSTRIAS FAMILIARES NO OESTE DO PARANÁ
}

\author{
SOCIOECONOMIC PROFILE OF HOLDERS OF FAMILY AGROINDUSTRIES \\ IN THE WEST OF PARANÁ
}

\section{PERFIL SOCIOECONÔMICO DOS TITULARES DE AGROINDÚSTRIAS FAMILIARES NO OESTE DO PARANÁ}

\author{
Fabíola Graciele Besen ${ }^{1}$ \\ https://orcid.org/0000-0002-8740-2920 \\ Clério Plein ${ }^{2}$ \\ https://orcid.org/0000-0002-7235-9771 \\ Juarez Bortolanza ${ }^{3}$ \\ https://orcid.org/0000-0003-0497-7946
}

Submissão: 13/07/2020 / Aceito: 19/11/2020 Publicado: 30/06/2021.

Resumo: Este trabalho consiste em um estudo exploratório descritivo de um conjunto de 35 agroindústrias de 8 municípios do Oeste do Paraná, obtidos por uma empresa de assessoramento técnico na região, relacionados aos aspectos socioeconômicos dos titulares destas agroindústrias. Uma revisão bibliográfica contribuiu na análise e apresentação dos resultados estudados. $\mathrm{O}$ uso de uma matriz para tomada de decisão possibilitou identificar a ordem de prioridade de iniciativas, tanto de políticas públicas quanto dos proprietários dos empreendimentos agropecuários viabilizando, ações para melhorar a atratividade desses empreendimentos com rentabilidade e bem-estar dos proprietários. Identificou-se que 15 agroindústrias familiares possuem apenas dois membros na propriedade e 09 possuem apenas 03 membros, totalizando um percentual de 68,6\% da amostra. A agroindústria contrata mão de obra terceirizada, mas identificou-se que apenas $22,9 \%$ faz uso dessa mão de obra. Há uma pequena predominância masculina na atividade. Quanto à matriz aplicada, os resultados ordenam a priorização de ações a serem desenvolvidas por meio de políticas públicas e/ou dos agricultores familiares para potencializar estabilidade e rendimentos em seus empreendimentos.

Palavras - chave: Demografia do Oeste do Paraná, agroindústrias familiares, ações aos empreendedores agropecuários.

Abstract: This work consists of an exploratory descriptive study of a group of 35 agroindustries in 8 municipalities in the west of Paraná, obtained by a technical advisory company in the region, related to the socioeconomic aspects of the holders of these agro-industries. A

\footnotetext{
${ }^{1}$ Bacharel em Ciências Contábeis. Mestre em Extensão Inovadora e Desenvolvimento Rural Sustentável. Atualmente, cursa doutorado em Desenvolvimento Rural Sustentável pela Universidade Estadual do Oeste do Paraná (Unioeste). Professora do Curso de Ciências Contábeis da Unioeste - Campus de Foz do Iguaçu. E-mail: fabiolagracielebesen@ gmail.com

${ }^{2}$ Doutor em Desenvolvimento Rural - Universidade Federal do Rio Grande do Sul - UFRGS. Professor Adjunto Curso Serviço Social Unioeste - Campus de Francisco Beltrão. E-mail: clerioplein@ gmail.com

${ }^{3}$ Pós - doutor em Gestão Universitária (UFSC - SC), Doutor em Engenharia da produção (UFSC - SC). Professor Adjunto do curso de Administração - UNIOESTE - MCR. juarezbortolanza@gmail.com
} 
bibliographic review contributed to the analysis and presentation of the studied results. The use of a matrix for decision making made it possible to identify the priority order of initiatives, both public policies and the owners of agricultural enterprises, enabling actions to improve the attractiveness of these enterprises with profitability and well-being of the owners. It was identified that 15 family agribusinesses have only two members on the property and 09 have only 03 members, totaling a percentage of $68.6 \%$ of the sample. The agribusiness hires outsourced labor, but it was found that only $22.9 \%$ make use of this labor. There is a small male predominance in the activity. As for the applied matrix, the results order the prioritization of actions to be developed through public policies and / or family farmers to enhance stability and income in their enterprises.

Keywords: Demography of Western Paraná, family agroindustries, actions for agricultural entrepreneurs.

Resumen: Este trabajo consiste en un estudio descriptivo exploratorio de un grupo de 35 agroindustrias en 8 municipios del occidente de Paraná, obtenido por una empresa de asesoría técnica de la región, relacionado con los aspectos socioeconómicos de los titulares de estas agroindustrias. Una revisión bibliográfica contribuyó al análisis y presentación de los resultados estudiados. El uso de una matriz para la toma de decisiones permitió identificar el orden de prioridad de las iniciativas, tanto de políticas públicas como de propietarios de empresas agrícolas, posibilitando acciones para mejorar el atractivo de estas empresas con rentabilidad y bienestar de los propietarios. Se identificó que 15 agroindustrias familiares tienen solo dos integrantes en la propiedad y 09 tienen solo 03 integrantes, totalizando un porcentaje del $68.6 \%$ de la muestra. La agroindustria contrata mano de obra tercerizada, pero se encontró que solo el 22,9\% hace uso de esta mano de obra. Hay un pequeño predominio masculino en la actividad. En cuanto a la matriz aplicada, los resultados ordenan la priorización de acciones a desarrollar a través de políticas públicas y / o agricultores familiares para mejorar la estabilidad y los ingresos en sus empresas.

Palabras clave: Demografía del Paraná occidental, agroindustrias familiares, acciones para empresarios agrícolas.

\section{INTRODUÇÃO}

O Povoamento do Oeste do Paraná ocorreu de forma planificada por companhias colonizadoras que, com incentivo do Governo Federal buscou ocupar os vazios demográficos e ocupação das áreas de fronteiras (MOTA, 2005). A migração de gaúchos e catarinenses a partir de 1930, denominada de frente sulista, ocupou a maior parte do sudoeste e parte do oeste paranaense (WACHOWICZ,2002; PRIORI et al. 2012) Entre as décadas de 1940 e 1950 a taxa anual de crescimento no Paraná foi de 5,61\%, entre 1959 a 1960 atingiu 7,165\% e com retração na década de 1960 a 1970 com 4,97\%, proporcionando um aumento populacional importante ao Estado e consequentemente no Oeste do mesmo (IBGE, 2010).

A partir da década de 1980, começou a estabilização do crescimento rural no Paraná diante das oportunidades fornecidas nas cidades. A força de atração das cidades pelo processo de industrialização urbana e dos meios de mecanização em larga escala agiram na repulsão 
da população do campo. $\mathrm{O}$ encontro de melhores condições de vida e financeira obtida pelo emprego o acesso a bens materiais, serviços e produtos, além da maior oferta de serviços públicos como hospitais e escolas, foram atrativos para o esvaziamento no campo.

A importância e a caracterização da agricultura familiar brasileira são de interesse de vários estudos sobre o meio rural, que por um lado destaca a produção de alimentos, geração de renda e inclusão social, por outro, enfrenta desafios para sua sustentabilidade. Um dos desafios é a insatisfação dos agricultores familiares diante dos resultados econômicos obtidos por meio das atividades agrícolas (WESZ JUNIOR, 2009).

As transformações constantes dos sistemas alimentares direcionam uma potencialidade para a agricultura familiar endossar a produção da alimentação saudável e recuperar sistemas alimentares para o bem-estar da população, mas também dependerá da capacidade da própria agricultura familiar de promover novas estratégias, capacidades e alianças (BERDEGUE, 2019).

No Brasil em 2017, havia 3.897.408 estabelecimentos classificados como agricultura familiar, abrangendo $77 \%$ dos estabelecimentos agropecuários, os quais ocupam uma área de 81 milhões de hectares, ou seja, $23 \%$ da área total dos estabelecimentos agropecuários brasileiros. A agricultura familiar responde por $23 \%$ do valor total da produção dos estabelecimentos e ocupa $77 \%$ de todo o pessoal em agropecuária no País, cerca de 10,1 milhões de pessoas (IBGE, 2017).

A produção rural, ao industrializar seus produtos, agrega um maior percentual de valor no produto e consegue aumentar seus rendimentos. A agroindústria familiar rural é "uma forma de organização em que a família rural produz, processa e/ou transforma parte de sua produção agrícola e/ou pecuária, visando, sobretudo, a produção de valor de troca que se realiza na comercialização, fortalece o direcionamento a agro industrialização" (MIOR, 2005, p. 191).

O desafio, portanto, do pequeno estabelecimento agroindustrial rural é buscar se posicionar em nichos de mercado, nos quais são valorizadas especificidades intrínsecas (físicas) ou extrínsecas (símbolos, imagem) do produto (SCHINAIDER et al, 2018). O processo de agroindustrialização é uma forma de desenvolvimento local e regional, uma vez que seus produtos são produzidos e processados em unidade familiar e no contexto local (WESZ JUNIOR; TRENTIN; FILLIPI, 2009). 
A relevância das agroindústrias rurais familiares (ARFs) no contexto socioeconômico e ambiental, faz parte de pesquisas com direcionamentos distintos, mas com intuito de proporcionar viabilidade e sustentabilidade às ARFs, com estratégias que possibilitam novos meios, procedimentos, alternativas para a reprodução socioeconômica delas.

Neste estudo objetiva-se caracterizar a demografia da região Oeste do Paraná; os aspectos socioeconômicos dos titulares de um conjunto de agroindústrias e; ordenar as prioridades de ações para potencializar as agroindústrias existentes bem como incentivar a implantação de novos empreendimentos nesta área.

Para atender a este questionamento, este trabalho está estruturado pelos seguintes tópicos: introdução, referencial teórico sobre o tema, metodologia; discussões dos resultados, uma ferramenta para auxiliar a tomada de decisão e finaliza com considerações finais, que complementa o trabalho, além das referências pesquisadas.

\section{REFERENCIAL TEÓRICO}

O Oeste paranaense, uma região de fronteira, até a década de 1920, esteve as margens da atenção do Estado, com predominância de língua espanhola e não a língua pátria, o peso argentino era a moeda em circulação, os habitantes em sua maioria com origem platina e os meios de transporte estavam sob o controle da Argentina e pela Companhia Mate Laranjeira, de origem paraguaia (STECA; FLORES, 2008).

A imensa campanha do governo federal para ocupação dos espaços pouco povoado, os chamados 'vazios demográficos' nas regiões de fronteira do território nacional (MOTA, 2005) desencadeou na década de 1930 a denominada 'marcha para o oeste' (WACHOWICZ, 1988, PRIORI et al. 2012), impulsionou o processo de colonização do Oeste do Paraná, principalmente, por migrantes de origem italiana e alemã, originários dos Estados de Santa Catarina e Rio Grande do Sul (PRIORI et al. 2012). A partir da década de 1950, o povoamento do Oeste do Paraná, ganhou força, pois além de catarinenses e gaúchos chegaram, mineiros e paulistas, bem como de imigrantes japoneses, italianos, portugueses, árabes e alemães (IPARDES, 2019a).

O aumento da população no Paraná e consequentemente no Oeste do Paraná, estão relacionadas as altas taxa de fecundidade, além do processo migratório ao estado, que foram determinantes no processo de povoamento. $\mathrm{O}$ aumento da população decorrente da taxa de fecundidade total (número médio de filhos que uma mulher teria ao final do seu período 
fértil) pode ser vista na Tabela 1 que demonstra o crescimento ocorrido a partir da década de 1940 e das décadas posteriores, com uma projeção os próximos anos, onde a taxa de fecundidade está em declínio e abaixo da reposição natural da população corresponde a 2,2 filhos.

TABELA 01 - Taxa de Fecundidade total e projetada da população no Brasil e Regiões, 1940 - 2050.

\begin{tabular}{|c|c|c|c|c|c|c|c|c|c|c|c|c|c|}
\hline \multirow{2}{*}{$\begin{array}{l}\text { Grandes } \\
\text { Regiões }\end{array}$} & \multicolumn{8}{|c|}{ Taxa de fecundidade total } & \multicolumn{5}{|c|}{ Projetada } \\
\hline & 1940 & 1950 & 1960 & 1970 & 1980 & 1991 & 2000 & 2010 & 2015 & 2020 & 2030 & 2040 & 2050 \\
\hline Brasil & 6,16 & 6,21 & 6,28 & 5,76 & 4,35 & 2,89 & 2,38 & 1,75 & 1,80 & 1,76 & 1,72 & 1,69 & 1,67 \\
\hline Norte & 7,17 & 7,97 & 8,56 & 8,15 & 6,45 & 4,20 & 3,16 & 2,21 & 2,11 & 2,00 & 1,88 & 1,83 & 1,81 \\
\hline Nordeste & 7,15 & 7,50 & 7,39 & 7,53 & 6,13 & 3,75 & 2,69 & 1,82 & 1,78 & 1,73 & 1,69 & 1,67 & 1,66 \\
\hline Sudeste & 5,69 & 5,45 & 6,34 & 4,56 & 3,45 & 2,36 & 2,10 & 1,63 & 1,73 & 1,70 & 1,68 & 1,65 & 1,63 \\
\hline Sul & 5,65 & 5,70 & 5,89 & 5,42 & 3,63 & 2,51 & 2,24 & 1,63 & 1,77 & 1,74 & 1,72 & 1,71 & 1,69 \\
\hline Centro-Oeste & 6,36 & 6,86 & 6,74 & 6,42 & 4,51 & 2,69 & 2,25 & 1,77 & 1,90 & 1,85 & 1,80 & 1,75 & 1,69 \\
\hline
\end{tabular}

Fonte: Censo 1940 a 2010 (IBGE, 2019).

A demografia sofreu considerável modificação fruto do crescimento e deslocamento da população, que passou de 41 milhões de habitantes em 1930, para 70 milhões em 1960 e a taxa de urbanização passou de 31 para 41\% (MARICATO, 2001; IBGE/SIS, 2002, 2003; IBGE/AEB, 2003). De acordo com dados da Pesquisa Nacional por Amostra de Domicílios (PNAD, 2015) em 2015 a maior parte da população brasileira, 84,72\%, vive em áreas urbanas enquanto outros $15,28 \%$ dos brasileiros viviam em áreas rurais.

Essa mobilização da população para a área urbana decorreu, também, pelo sistema de mecanização empregado para produção agrícola em larga escala no decorrer dos anos. $\mathrm{O}$ movimento de forte migração das áreas rurais para as cidades, determinou o crescimento desordenado de grandes aglomerações e a formação de centros metropolitanos, que são reflexos dessa dinâmica. (JACINTO, MENDES e PEREHOUSKEI, 2012, MARQUES, 2014).

A PEA (população economicamente ativa) agrícola vem diminuindo nas últimas décadas, principalmente no meio rural, registrando redução de $20 \%$ durante o período 20042014 (passou de aproximadamente 18 milhões de pessoas para 14,5 milhões) (EMBRAPA, 2018). Essa mobilidade e dinâmica demográfica da população ocorreu de maneira similar no Paraná, com uma concentração maior da população residente em áreas rurais até a década de 1980, quando passou a equilibrar e a ter predomínio dos residentes no meio urbano. A Tabela 02 apresenta o crescimento ocorrido em termos populacionais e sua localização. 
Tabela 02 - População Urbana e Rural - Paraná (1950 a 2020)

\begin{tabular}{lcclrl}
\hline Ano & População & População Urbana & \% & População Rural & \% \\
\hline 1950 & 2.115 .547 & 528.252 & 24,97 & 1.598 .296 & 75,55 \\
1960 & 4.277 .763 & 1.327 .818 & 31,04 & 3.209 .606 & 75,03 \\
1970 & 6.997 .682 & 2.547 .156 & 36,40 & 4.450 .526 & 63,60 \\
1980 & 7.749 .752 & 4.566 .929 & 58,93 & 3.182 .823 & 41,07 \\
1991 & 8.443 .299 & 6.193 .160 & 73,35 & 2.250 .139 & 26,65 \\
1996 & 9.003 .804 & 6.941 .032 & 77,09 & 2.062 .772 & 22.91 \\
2000 & 9.563 .458 & 7.784 .655 & 81,40 & 1.520 .590 & 15,90 \\
2010 & 10.439 .601 & 8.906 .024 & 85,31 & 1.533 .577 & 14,69 \\
2020 & $11.538 .518^{*}$ & & & & \\
\hline
\end{tabular}

Fonte: IBGE, Censo Demográfico 1950/2010 (2019).

* IBGE/Diretoria de Pesquisas. Coordenação de População e Indicadores Sociais. Gerência de Estudos e Análises da Dinâmica Demográfica. Projeção da população do Brasil por sexo e idade para o período 20002060 .

O crescimento da população paranaense, tende a ser em municípios de maior porte, pois em 2010, computava 18 municípios com 100 mil ou mais habitantes, cujo quantitativo deverá ser de 23 até 2040 (IBGE 2019). Este conjunto de municípios de maior porte, terão um incremento populacional maior, passando dos 49,3\% para 57,5\% neste período considerando que corresponde a uma taxa de crescimento maior que a do vegetativo natural da população no país e/ou da região. Isto significa, consequentemente, uma migração populacional dos municípios de menor porte, principalmente com menos de 20 mil habitantes, os quais sofrerão uma redução de $3,4 \%$ de sua população durante este período (IBGE, 2019).

O Oeste do Paraná é constituído por um conjunto 50 municípios, segundo o Instituto Paranaense de Desenvolvimento Econômico e Social (IPARDES, 2019a), quais sejam: Anahy, Assis Chateaubriand, Boa Vista da Aparecida, Braganey, Cafelândia, Campo Bonito, Capitão Leônidas Marques, Cascavel, Catanduvas, Céu Azul, Corbélia, Diamante do Sul, Diamante D'Oeste, Entre Rios do Oeste, Formosa do Oeste, Foz do Iguaçu, Guaíra, Guaraniaçu, Ibema, Iguatu, Iracema do Oeste, Itaipulândia, Jesuítas, Lindoeste, Marechal Cândido Rondon, Maripá, Matelândia, Medianeira, Mercedes, Missal, Nova Aurora, Nova Santa Rosa, Ouro Verde do Oeste, Palotina, Pato Bragado, Quatro Pontes, Ramilândia, Santa Helena, Santa Lúcia, Santa Tereza do Oeste, Santa Terezinha de Itaipu, São José das Palmeiras, São Miguel do Iguaçu, São Pedro do Iguaçu, Serranópolis do Iguaçu, Terra Roxa, Toledo, Três Barras do Paraná, Tupãssi e Vera Cruz do Oeste.

O crescimento e a concentração da população nos municípios de maior porte, também devem ocorrer no Oeste do Paraná, cuja população atual de 1.315.226 habitantes, 55,3\% 
estão concentradas nos três principais municípios do Oeste do Paraná que equivale a 727.621 habitantes. Em outra perspectiva, $78 \%$ dos municípios do Oeste do Paraná tem uma população inferior a 20 mil habitantes e, praticamente $25 \%$ dos municípios tem uma população inferior a 5 mil munícipes (IBGE, 2019). A Tabela 3 apresenta a composição populacional do Brasil, Paraná e do Oeste do Paraná, demonstrando a correlação entre eles.

TABELA 03 - Tamanho e concentração da População do Brasil, Paraná e Oeste do Paraná

\begin{tabular}{|c|c|c|c|c|c|c|c|c|c|}
\hline População & Brasil & Acumulado & $\%$ & Paraná & Acumulado & $\%$ & $\begin{array}{l}\text { Oeste } \\
\text { Paraná } \\
\end{array}$ & Acumulado & $\%$ \\
\hline até 5000 & 1.253 & - & - & 102 & - & - & 12 & - & 24 \\
\hline até 10.000 & 1.199 & 2.452 & 44 & 100 & 202 & 51 & 14 & 26 & 52 \\
\hline até 20.000 & 1.345 & 3.797 & 68 & 104 & 306 & 77 & 13 & 39 & 78 \\
\hline até 50.000 & 1.100 & 4.897 & 88 & 57 & 363 & 91 & 7 & 46 & 92 \\
\hline até 100.000 & 349 & 5.246 & 94 & 15 & 378 & 95 & 1 & 47 & 94 \\
\hline até 500.000 & 276 & 5.522 & 99 & 19 & 397 & 99 & 3 & 50 & 100 \\
\hline $\begin{array}{ll}\text { mais } & \text { de } \\
500.000 & \\
\end{array}$ & 48 & 5.570 & 100 & 2 & 399 & 100 & - & - & - \\
\hline TOTAL & 5.570 & & & 399 & - & - & 50 & - & - \\
\hline
\end{tabular}

FONTE: IBGE, IPARDES (2019a).

A concentração da população em área urbana dos principais municípios do Oeste do Paraná, é superior à média estadual e nacional, pois Foz do Iguaçu, dada a sua constituição e localização geográfica, concentra 99,17\% de sua população em área urbana, Cascavel tem 94,30\% de sua população residente em área urbana, e Toledo tem 90,74\% de sua população urbana. Entretanto os municípios de menor porte têm uma concentração e população maior no meio rural, diante das próprias atividades e forte cunho agropecuários dos municípios (IBGE, 2019).

Este trabalho concentra a atenção para um conjunto de 8 municípios, do Oeste do Paraná, descritos na Tabela 4, a qual contempla uma abordagem contextualizando informações referente aos municípios do estudo. 
Revista Grifos - Unochapecó

Tabela 4 - Caracterização dos municípios do Oeste do Paraná das agroindústrias estudadas.

\begin{tabular}{|c|c|c|c|c|c|c|c|c|c|}
\hline Município & $\begin{array}{l}\text { Área } \\
\text { Km2 }\end{array}$ & Emancipação & $\begin{array}{c}\text { Colonização } \\
\text { predominant } \\
\text { e }\end{array}$ & $\begin{array}{c}\text { População } \\
\text { total }\end{array}$ & $\begin{array}{c}\text { População } \\
\text { urbana }\end{array}$ & $\begin{array}{c}\text { Urbano } \\
\%\end{array}$ & $\begin{array}{l}\text { População } \\
\text { rural }\end{array}$ & $\underset{\%}{\text { Rural }}$ & $\begin{array}{l}\text { IDH } \\
2010\end{array}$ \\
\hline CÉU AZUL(1) & $1.180,163$ & $\begin{array}{c}1968 \\
\text { MATELÂNDIA }\end{array}$ & $\begin{array}{l}\text { Alemã, } \\
\text { Italiana (RS, } \\
\text { SC) }\end{array}$ & 11.709 & 8.387 & 71,63 & 2.645 & 28,37 & 0,732 \\
\hline $\begin{array}{l}\text { ENTRE RIOS } \\
\text { DO OESTE (2) }\end{array}$ & 120,327 & $\begin{array}{c}1993 \\
\text { MAL CDO } \\
\text { RONDON }\end{array}$ & $\begin{array}{l}\text { Alemã, } \\
\text { Italiana (RS, } \\
\text { SC) }\end{array}$ & 4.481 & 2.642 & 58,96 & 1.284 & 41,04 & 0,761 \\
\hline GUAÍRA (3) & 568,845 & $\begin{array}{c}1952 \\
\text { FOZ DO } \\
\text { IGUAÇU }\end{array}$ & $\begin{array}{l}\text { Diversas } \\
\text { Etnias }\end{array}$ & 32.923 & 28.206 & 85,67 & 2.498 & 14,33 & 0,724 \\
\hline $\begin{array}{l}\text { MATELÂNDIA } \\
\text { (4) }\end{array}$ & 642,030 & $\begin{array}{c}1961 \\
\text { (FOZ DO } \\
\text { IGUAÇU }\end{array}$ & $\begin{array}{l}\text { Alemã, } \\
\text { Italiana (RS, } \\
\text { SC) }\end{array}$ & 17.775 & 11.613 & 65,33 & 4.465 & 34,67 & 0,725 \\
\hline $\begin{array}{l}\text { MEDIANEIRA } \\
\text { (5) }\end{array}$ & 325,167 & $\begin{array}{c}1961 \\
\text { FOZ DO } \\
\text { IGUAÇU }\end{array}$ & $\begin{array}{l}\text { Alemã, } \\
\text { Italiana (RS, } \\
\text { SC) }\end{array}$ & 45.812 & 37.390 & 81,62 & 4.427 & 18,38 & 0,763 \\
\hline $\begin{array}{l}\text { PATO } \\
\text { BRAGADO (6) }\end{array}$ & 136,781 & $\begin{array}{c}1993 \\
\text { MAL CDO } \\
\text { RONDON }\end{array}$ & $\begin{array}{l}\text { Alemã, } \\
\text { italiana (RS, } \\
\text { SC) }\end{array}$ & 5.535 & 2.993 & 54,07 & 1.829 & 45,93 & 0,747 \\
\hline $\begin{array}{l}\text { SÃO PEDRO } \\
\text { DO IGUAÇU (7) }\end{array}$ & 308,123 & $\begin{array}{c}1993 \\
\text { TOLEDO }\end{array}$ & $\begin{array}{l}\text { Alemã, } \\
\text { italiana (RS, } \\
\text { SC), } \\
\text { Mineiros e } \\
\text { nordestinos }\end{array}$ & 5.976 & 4.055 & 67,85 & 2.436 & 32,15 & 0,683 \\
\hline $\begin{array}{l}\text { VERA CRUZ } \\
\text { DO OESTE (8) }\end{array}$ & 326,398 & $\begin{array}{c}1983 \\
\text { CÉU AZUL }\end{array}$ & $\begin{array}{l}\text { Norte do } \\
\text { Paraná }\end{array}$ & 8.590 & 6.863 & 79,90 & 2.110 & 20,10 & 0,699 \\
\hline TOTAL & $3.607,83$ & _ & _ & 132.801 & 102.149 & 76,91 & 21.694 & 23,09 & _ \\
\hline
\end{tabular}

Fonte: (1) IPARDES (2019b); (2) IPARDES (2019c); (3) IPARDES (2019d); (4) IPARDES (2019e); (5) IPARDES (2019f); (6) IPARDES (2019g); (7) IPARDES (2019h) e (8) IPARDES (2019i) adaptado pelos autores.

Os municípios considerados, são relativamente de pequeno porte e suas populações com predominância em áreas urbanas, mas com considerável população em áreas rurais, onde $50 \%$ dos mesmos, detém mais de $30 \%$ de sua população em área rural, indicando que esforços de políticas públicas devem ter atenção a proporcionar condições sustentáveis e bem-estar desta população para sua permanência em seu habitat atual.

Uma apreciação de forma abrangente pode ser feita pela leitura do Índice de Desenvolvimento Humano (IDH), onde o Brasil, no mesmo período de 2010, apresentava IDH 0,699, e o estado do Paraná com IDH 0,749, permitindo identificar, de maneira abrangente, as condições de vida da população em cada município (IBGE, 2010).

Conforme o registro na Tabela 04, os municípios relacionados neste trabalho, contemplam seu IDH, próximos ao do Estado do Paraná, sem contudo predizer que não comporta melhorias aos mesmos, como na área rural, potencializando as atividades agropecuárias por meio do fortalecimento os estabelecimentos agropecuários principalmente os voltados a agregar valor aos seus produtos por meio da agroindustrialização.

O estabelecimento agropecuário é toda unidade de produção ou exploração dedicada, total ou parcialmente, a atividades agropecuárias, florestais ou aquícolas, independentemente 
de seu tamanho, de sua forma jurídica (se pertence a um produtor, a vários produtores, a uma empresa, a um conjunto de empresas), ou de sua localização (área urbana ou rural), tendo como objetivo a produção, seja para venda (comercialização da produção), seja para subsistência (sustento do produtor ou de sua família) ( NITAHARA, 2019).

Neste sentido, o fortalecimento dos estabelecimentos agropecuários, com políticas públicas, pode contribuir na permanência deste contingente humano em áreas rurais, proporcionando melhores condições ao atender as reivindicações das agroindústrias e dos proprietários dos empreendimentos agropecuários, evitando ou diminuindo os conflitos sociais que acompanham os processos da urbanização, quando não atendem a contento a população.

No encontro de obter estabilidade em seus empreendimentos os agricultores familiares, no decorrer dos anos, aprimoraram os meios de produção e principalmente de diversificação agrícola, para a obtenção adicional de renda às propriedades. A concentração demográfica predominante no meio rural, em décadas anteriores, passou a ser menos representativa, a partir da década de 1980, além dos inúmeros desafios como: comercialização de sua produção sem depender de intermediários, instabilidade climática, não ocorrência da sucessão hereditária, variação nos preços de insumos e da produção, dentre outros, passaram a ter limitação de recursos humanos ao trabalho na agricultura Nesse sentido, faz-se necessária a busca por alternativas produtivas, buscando viabilizar a agricultura familiar, com atividades pluriativas e estratégicas, entre as quais se destaca a agroindústria, por permitir agregar mais valores aos produtos e proporcionar força a renda da família no campo (KAGEYAMA, 2003; WESZ JUNIOR, 2009, FOGUESATTO; MACHADO, 2017).

A agroindústria familiar rural é "uma forma de organização em que a família rural produz, processa e/ou transforma parte de sua produção agrícola e/ou pecuária, visando, sobretudo, a produção de valor de troca que se realiza na comercialização, fortalece o direcionamento a agro industrialização” (MIOR, 2005, p. 191).

As agroindústrias rurais em sua maioria configuradas como micro ou pequenas organizações empresariais, nas quais ocorrem os processos de beneficiamento, processamento e transformação de determinadas matérias-primas rurais até a etapa de comercialização apresentam como características principais: i) produção e comercialização em pequena escala, ii) empreendimentos pulverizados em diferentes locais, iii) o 
desenvolvimento de produtos, considerando aspectos culturais, sociais e ecológicos, além dos aspectos formais de produção e comercialização (PREZOTTO, 2002; ARAÚJO, 2005, BREITENBACH et al., 2017).

\section{Metodologia}

O delineamento da pesquisa se constituiu pela pesquisa bibliográfica. Conforme Andrade et al (2016, p.52) "trata-se de estratégia de pesquisa necessária para a condução de qualquer pesquisa científica. Uma pesquisa bibliográfica procura explicar e discutir um assunto, tema ou problema com base em referências publicadas em livros, periódicos, revistas, jornais, sites, anais de congressos."

Este trabalho parte de um estudo exploratório descritivo das informações contidas no "Projeto Análise socioeconômica das Agroindústrias da BP3", da Cooperativa de Trabalho e Assistência Técnica do Paraná (BIOLABORE) em conjunto com a Itaipu Binacional, por meio do Projeto Desenvolvimento Rural Sustentável - Programa Cultivando Água Boa da Itaipu Binacional. A BP3 - Bacia do Paraná 3, localizada no extremo Oeste do Paraná, comporta o atendimento a 124 agroindústrias, pela Biolabore, através de ATER - Assistência Técnica e Extensão Rural, durante o período de 04/2015 a 04/2018. Os municípios com as 35 agroindústrias que fazem parte deste trabalho, no Oeste do Paraná compreendem: (Céu Azul, Entre Rios do Oeste, Guaíra, Matelândia, Medianeira, Pato Bragado, São Pedro do Iguaçu e Vera Cruz do Oeste).

A pesquisa se classifica como um estudo de caso, no caso, que segundo Gil (2019, p.62) é "uma modalidade de pesquisa amplamente utilizada nas ciências sociais. Consiste no estudo profundo e exaustivo de um ou poucos casos, de maneira que permita seu amplo e detalhado conhecimento".

Os principais aspectos estudados e apresentados são: taxas de fecundidade da população, distribuição da população entre urbana e rural, identificação do tamanho dos municípios, caracterização dos municípios estudados, quantificação das agroindústrias, descrição da mão de obra e contratada, gênero e faixa etária dos titulares, tempo dedicado às atividades agroindustriais e a renda oriunda da agroindústria e outras rendas. 
A abordagem é quantitativa, pois fez uso dos dados extraídos dos diagnósticos das 35 agroindústrias, amostra da pesquisa, que foram tabulados e inseridos em software de gerenciamento estatístico próprio para proceder suas análises quantitativas.

Após análise da demografia e do perfil dos titulares das agroindústrias, o estudo propõe uma discussão a partir da construção de uma matriz que analisa a Gravidade, Urgência e Tendência (GUT). Este método racional estabelece uma ordem numérica de prioridades entre um dado conjunto de opções, além de estabelecer a importância aos problemas, proporcionando direcionamento mais assertivo para um planejamento mais embasado e com detalhes e estrutura técnicas. A Ferramenta conhecida por GUT, ou Matriz GUT, estabelece dentre os problemas verificados uma matriz possibilitando analisar a Gravidade, Urgência e Tendência dos problemas. O estabelecimento do valor a cada elemento de avaliação, retrata as condições de cada agroindústria e, ao seu conjunto, dada a familiaridade de problemáticas existentes, que foram atribuídos pelos autores diante da experiência e seus conhecimentos empíricos.

Tabela 5 - Valores da Gravidade X Urgência X Tendência que estabelecem as prioridades

\begin{tabular}{ccccc}
\hline VALOR & GRAVIDADE & URGÊNCIA & TENDÊNCIA & $\mathrm{G} \times \mathrm{U} \times \mathrm{T}$ \\
\hline 5 & os prejuízos ou dificuldades & É necessária uma ação & $\begin{array}{c}\text { se nada for feito a situação irá } \\
\text { piorar rapidamente }\end{array}$ \\
& são extremamente graves & imediata & com alguma urgência & vai piorar em pouco tempo \\
4 & muito graves & vraves & o mais cedo possível & vai piorar a médio prazo \\
3 & pouco graves & pode esperar um & vai piorar a longo prazo \\
2 & pem gravidade & não tem pressa & não irá mudar \\
& & &
\end{tabular}

Fonte: PERIARD, 2011.

\section{ANÁLISE DOS DADOS}

\section{Características das 35 Agroindústrias Familiares do Oeste do Paraná, 2015-2018}

A existência de agroindústrias em cada município pode ser entendida por inúmeras variáveis, partindo de políticas públicas, que possam incentivar a implantação e o fortalecimento delas, interesse dos proprietários dos empreendimentos agropecuários, aptidão e iniciativa para produzir algo diferenciado ou com boas maneiras de produção, estudos de mercado, com vistas a assegurar destino aos produtos de forma competitiva e viável as agroindústrias, assegurar instalações, maquinários, tecnologias e meios para a produção em atendimento as questões legais, entre outros. O mercado, como conjunto de consumidores reais e potenciais de determinado produto ou serviços (KOTLER, 2003), pode 
ser trabalhado pela comunidade, despertando interesse pelo uso e/ou consumo dos produtos produzidos pelos agroindustriais.

O número de agroindústrias em cada município considerado neste trabalho, a oferta de mão de obra familiar em suas agroindústrias bem como a necessidade de uso de mão de obra terceirizada, para executar as atividades necessárias em cada agroindústria, estão espelhadas na Tabela 6 e 7 , respectivamente:

Tabela 6 - Quantidade de Agroindústrias familiares por município no Oeste do Paraná 2015-2018.

\begin{tabular}{|c|c|c|}
\hline Municípios & Número de Agroindústrias familiares & Porcentagem \\
\hline CÉU AZUL & 2 & 5,7 \\
\hline ENTRE RIOS DO OESTE & 3 & 8,6 \\
\hline GUAÍRA & 3 & 8,6 \\
\hline MATELÂNDIA & 2 & 5,7 \\
\hline MEDIANEIRA & 15 & 42,9 \\
\hline PATO BRAGADO & 5 & 14,3 \\
\hline SÃO PEDRO DO IGUAÇU & 3 & 8,6 \\
\hline VERA CRUZ DO OESTE & 2 & 5,7 \\
\hline TOTAL & 35 & 100,0 \\
\hline
\end{tabular}

Fonte: Dados da pesquisa (2019).

A tabela 7 apresenta o uso da mão de obra, recurso imprescindível a agroindústria, pela limitação de disponibilidade de pessoas para a realização das atividades agroindustriais, seja familiar ou contratada.

Tabela 7 - Mão de Obra das 35 Agroindústrias Familiares do Oeste do Paraná, 2015-2018

\begin{tabular}{c|c|c|c|c|c}
\hline \multicolumn{2}{c}{ Familiar } & \multicolumn{3}{c}{ Contratada } \\
\hline $\begin{array}{c}\text { Qtde } \\
\text { agroindústrias }\end{array}$ & Qtde membros & $\%$ & $\begin{array}{c}\text { Qtde } \\
\text { agroindústrias }\end{array}$ & Qtde membros & \% \\
\hline 15 & 2 & 42,9 & 4 & 1 & 11,4 \\
9 & 3 & 25,7 & 2 & 2 & 5,7 \\
6 & 4 & 17,1 & 1 & 4 & 2,9 \\
2 & 1 & 5,7 & 1 & 5 & 2,9 \\
2 & 5 & 5,7 & 27 & 0 & 77,1 \\
1 & 9 & 2,9 & & & $\mathbf{1 0 0}$ \\
\hline
\end{tabular}

Fonte: Dados da pesquisa (2019) 
A apropriação e agregação de valor aos produtos produzidos nos estabelecimentos agropecuários, fazem parte de uma conjuntura de condições, que podem potencializar ou minimizar o uso dos produtos originários das propriedades. Entre outros fatores está a disponibilidade de mão de obra, para o processamento, transformação, industrialização que possam proporcionar maior rentabilidade aos estabelecimentos agropecuários.

$\mathrm{Na}$ Tabela 7, identificou-se que 15 agroindústrias familiares possuem apenas dois membros na propriedade e 09 possuem apenas 03 membros, totalizando um percentual de 68,6\% da amostra. Ainda de acordo com a Tabela 7, a agroindústria contrata mão de obra terceirizada, mas identificou-se que apenas $22,9 \%$ faz uso dessa mão de obra. Dois fatores podem contribuir para a contratação dessa mão de obra: poucos membros da família na propriedade, conforme identificado na Tabela 06 (acima) ou períodos de sazonalidade, em que aumenta o trabalho no processo de produção e industrialização.

Esta disponibilidade de mão de obra, retratada na Tabela 7, consiste num potencial as agroindústrias, por permitir agregar conhecimentos dos agroindustriais com particularidades específicas e únicas, que podem ser um diferencial competitivo e de agregação de valor aos produtos/serviços. Todavia, podem ser entrave pela carência de mão de obra, inibindo ou limitando a oportunidade de agregar mais valor aos produtos dos estabelecimentos agropecuários.

A tabela 8 contempla a faixa etária e gênero dos titulares das agroindústrias, que permite interpretar a força de produção dos estabelecimentos agropecuários.

Tabela 8 - Gênero e Faixa Etária do Titular das 35 Agroindústrias Familiares Oeste do Paraná, 2015-2018

\begin{tabular}{l|c|c|c}
\hline \multirow{2}{*}{ Faixa Etária } & \multicolumn{2}{c|}{ Gênero do Titular } & \multirow{2}{*}{ Total } \\
\cline { 2 - 3 } De 30 a 39 anos & Masculino & Feminino & 2 \\
De 40 a 49 anos & 2 & 0 & 9 \\
De 50 a 59 anos & 3 & 6 & 15 \\
De 60 a 69 anos & 7 & 8 & 8 \\
De 70 anos ou mais & 7 & 1 & 1 \\
\hline \multicolumn{1}{c}{ Total } & 1 & 0 & 35 \\
\hline
\end{tabular}

Fonte: Dados da pesquisa (2019).

A leitura da Tabela 8 demostra a inexistência de jovens em atividade nas agroindústrias, o que pode por si só, demonstrar que os estabelecimentos agropecuários 
podem não ter sucessores em suas atividades. Os jovens principalmente do sexo feminino, vêm deixando o meio rural em busca de melhores oportunidades de emprego e renda, estabilidade econômica e prestígio social das ocupações. Esse é um dos motivos para o desenvolvimento de políticas públicas voltadas para as agroindústrias familiares, que possibilita agregar valor aos produtos, dar novas visões de seus empreendimentos agropecuários e satisfação com rentabilidade aos mesmos (CAMARARO \& ABRAMOVAY, 1999)

A pequena predominância masculina, nas agroindústrias, consiste numa força em específico, que pode ser mais bem interpretada quando investigada ou analisadas as mesmas de maneira particularizada, que pode provavelmente decorrer dos conhecimentos empíricos ou de auto realização e satisfação em executar tal atividade em cada unidade agroindustrial. A execução de outras atividades desempenhada pelo gênero feminino nos empreendimentos agropecuários, podem limitar sua participação nas agroindústrias frente as demais afazeres culturalmente atribuídos as mulheres, como os domésticos, cuidados do lar e filhos. Por sua vez, a busca de realização pessoal, por meio da satisfação em realizar certas atividades nos empreendimentos agroindustriais, sempre fez parte das atividades agrícolas familiares, com a elaboração artesanal de produtos dentro da própria cozinha, ou mesmo como um meio de subsistência, para permanecer no meio rural.

A permanência no meio rural voltados com atenção a agroindústria, faz parte de $57 \%$ dos módulos agroindustriais, nos quais a mão de obra é integral a esta atividade, o que demonstra a que esta é principal fonte de trabalho e obtenção de renda nestes empreendimentos agropecuários. Com "atenção parcial" as atividades de agroindustrialização, fazem parte de $40 \%$ dos empreendimentos e a dedicação "atenção eventual" a agroindústria contempla um conjunto de apenas um estabelecimento agropecuário. As atividades agroindustriais, por sua natureza produtiva, podem ser afetadas por diversos fatores externos, e incontroláveis aos estabelecimentos agropecuários nas atividades agroindustriais. Nas operações agrícolas, existe alto grau de incerteza, resultante da perecibilidade da produção e da existência de uma organização de colheitas sazonais. Aliado à possibilidade de eventos climáticos desfavoráveis, pode-se imaginar a incerteza existente também sob o comportamento do consumidor (SCHINAIDER et al, 2018).

Políticas governamentais, com incentivos ou retração de algumas atividades podem interferir diretamente nos produtos produzidos em suas propriedades, o mercado 
internacional, pode promover elevação de preços ou diminuir os mesmos a patamares que podem ser inviáveis a produção, a competitividade interna ou no mercado local podem ser fatores que afetam a agroindústria. As condições climáticas, intempéries, excesso de chuva, seca, geada, chuva de granizo, entre outros, podem interferir e até causar a perda total de um período produtivo, ou safra. Tais fatores interferem na renda e/ou na rentabilidade das agroindústrias constante na Tabela 9, demonstra as diferenças de renda entre os agroindustriais.

Tabela 9 - Fonte de renda das 35 Agroindústrias Familiares do Oeste do Paraná - 2015-2018

\begin{tabular}{|c|c|c|c|c|c|c|}
\hline \multirow[b]{2}{*}{ Renda em SM } & \multicolumn{2}{|c|}{ Agroindústria } & \multicolumn{2}{|c|}{ Outras rendas } & \multicolumn{2}{|c|}{ Renda Total } \\
\hline & Qtde & $\%$ & Qtde & $\%$ & Qtde & $\%$ \\
\hline Até 2 & 12 & 34 & 16 & 46 & 8 & 23 \\
\hline 2 a 4 & 11 & 32 & 12 & 34 & 6 & 17 \\
\hline $4 \mathrm{ou}+$ & 12 & 34 & 7 & 20 & 21 & 60 \\
\hline Total & 35 & 100 & 35 & 100 & 35 & 100 \\
\hline
\end{tabular}

Fonte: Dados da pesquisa (2019).

A renda vista de forma direta e crua, pode ser interpretada de forma equivocada por não demonstrar a amplitude que deve ser analisada a condição da agroindústria e principalmente dos estabelecimentos agropecuários. A representação financeira direta de um único ano contábil, ou ano de base de coleta dos dados, pode ser um ano favorável, que por sua vez pode não representar a real rentabilidade líquida aos agroindustriais e dos seus empreendimentos agropecuários consequentemente.

Fogem do escopo de investigação deste trabalho, as condições de financiamentos existente, realizados, ou de pagamentos de dividendos de anos anteriores. Os resultados negativos de anos anteriores e que podem ser saldados, totalmente ou em parte num ano adequado, podem ser decorrentes de ocorrências de produções frustradas, formação de uma reserva de capital para a própria manutenção de toda infraestrutura da propriedade ou da própria desvalorização ou depreciação natural dos empreendimentos, maquinários entre outros. Entretanto, a receita total dos empreendimentos agropecuários e das agroindústrias não contemplam nada que possa brilhar como uma fonte próspera de obtenção de rentabilidade financeira.

Identificou-se a pluriatividade de atividades econômicas nas agroindústrias analisadas, além das atividades agropecuárias e agroindustriais. A pluriatividade na 
agricultura familiar são as situações onde os membros da família passam a realizar outras atividades econômicas e produtivas caracterizadas como não-agrícolas, praticadas dentro ou fora das propriedades nesse sentido, a realização de atividades pluriativas pode ser uma importante estratégia. (SCHNEIDER, 2003).

Considerando que as agroindústrias comportam 2 ou mais pessoas e com uma rentabilidade de até 2 salários mínimos para 34\% dos empreendimentos, pode-se inferir que a labuta e satisfação pessoal são fatores que direcionam os agroindustriais, além do resultado econômico.

\section{Ordem das Prioridades, obtidos pela MATRIZ GUT, para fortalecer as agroindústrias nos municípios.}

Em 1965, houve a publicação do livro “THE NATIONAL MANEGER”, uma obra que contém uma abordagem da administração, principalmente relacionadas a problemas e tomadas de decisão. O livro começa com a pergunta investigativa e desafiadora: De que modo os administradores resolvem problemas? Com esta pergunta inicial, os autores desenvolvem uma investigação, metodologias e apresentam procedimentos para encontrar soluções aos problemas organizacionais (KEPNER e TREGOE, 1965).

Desta forma a análise do problema e a tomada de decisão devem ser atos conscientes e sistematicamente executados e se necessário registrados nas organizações. A ausência deste método de procedimento leva a ineficiência, desperdícios, pois tanto a análise do problema quanto a tomada de decisão são funções importantes ao estabelecimento de objetivos e aos padrões de desempenho (KEPNER e TREGOE, 1981).

O Método GUT foi desenvolvido por Kepner e Tregoe na década de 1980, a partir da necessidade de resolução de problemas complexos nas indústrias americanas e japonesas. Várias contrariedades podem surgir em uma organização, e nem sempre é possível resolver todas ao mesmo tempo (KEPNER e TREGOE, 1981). O questionamento destes elementos fundamentais possibilita a priorização dos problemas para a tomada de decisão, o relacionamento entre si e amplas abordagens para a solução de problemas (KEPNER e TREGOE, 1981).

Esta indagação já conhecida no meio científico, é mais explicativa e compreensível através da construção da matriz. Esta matriz pode ser construída com critérios específicos na 
ponderação de valores contudo a mais usual corresponde aos da Tabela 10. Quanto mais impactante for a consideração, maior o valor a ser atribuído a questão em cada uma das premissas consideradas: Gravidade; Urgência e Tendência. A leitura dos valores atribuídos permite identificar o estabelecimento, de forma ordenada, dos apontamentos considerados em cada atribuição descrita, e em sua somatória retrata a ordem de efetivação das atividades dada a importância ou relevância de cada item considerado.

\begin{tabular}{ccccc}
\multicolumn{5}{c}{ Tabela $10-$ Valores da Gravidade X Urgência X Tendência que estabelecem as prioridades } \\
\hline VALOR & GRAVIDADE & URGÊNCIA & TENDÊNCIA & G X U x T \\
\hline 5 & os prejuízos ou dificuldades & É necessária uma ação & se nada for feito a situação irá \\
& são extremamente graves & imediata & piorar rapidamente \\
4 & muito graves & com alguma urgência & vai piorar em pouco tempo \\
3 & Graves & o mais cedo possível & vai piorar a médio prazo \\
2 & pouco graves & pode esperar um pouco & vai piorar a longo prazo \\
1 & sem gravidade & não tem pressa & não irá mudar \\
\hline
\end{tabular}
Fonte: PERIARD, 2011.

Este método racional estabelece uma ordem numérica de prioridades entre um dado conjunto de opções, além de estabelecer a importância aos problemas, proporcionando direcionamento mais assertivo num planejamento mais embasado e com detalhes e estrutura técnicas. Para melhor compreender a aplicação e potencialidades de uso da Matriz GUT, no contexto deste estudo, foram descritas e analisadas pelos autores as principais questões consideradas nas tabelas anteriores:

Tabela 11 - Prioridades de ações para sustentabilidade das agroindústrias

\begin{tabular}{|c|c|c|c|c|c|}
\hline ASPECTOS & Grav & Urg & Tend & GxUxT & Classificação \\
\hline $\begin{array}{l}\text { Caracterização dos municípios das indústrias } \\
\text { analisadas }\end{array}$ & 3 & 2 & 3 & 18 & $6^{\mathbf{0}}$ \\
\hline $\begin{array}{l}\text { Quantidade de Agroindústrias familiares por } \\
\text { município do Oeste do Paraná 2015- } 2018\end{array}$ & 3 & 4 & 5 & 60 & $\mathbf{1}^{\mathbf{o}}$ \\
\hline $\begin{array}{l}\text { Descrição da mão de obra das } 35 \text { Agroindústrias } \\
\text { Familiares do Oeste do Paraná, 2015-2018 }\end{array}$ & 3 & 3 & 4 & 36 & $3^{\mathbf{o}}$ \\
\hline $\begin{array}{l}\text { Gênero e Faixa Etária do Titular das } 35 \\
\text { Agroindústrias Familiares Oeste do Paraná, 2015- } \\
2018\end{array}$ & 4 & 3 & 4 & 48 & $2^{\circ}$ \\
\hline $\begin{array}{l}\text { Tempo do titular dedicado a Atividade de Agro } \\
\text { industrialização }\end{array}$ & 3 & 3 & 3 & 27 & $5^{\circ}$ \\
\hline $\begin{array}{l}\text { Fonte de renda das } 35 \text { Agroindústrias Familiares do } \\
\text { Oeste do Paraná 2015-2018 }\end{array}$ & 2 & 3 & 4 & 24 & $4^{\circ}$ \\
\hline
\end{tabular}

Fonte: Elaborado pelos autores.

A Matriz GUT, por ser uma ferramenta de gestão, permite identificar as prioridades das ações sejam por meio de políticas públicas, com ações importantes dos governantes, e/ou pelos próprios agroindustriais, as quais precisam ser efetivadas com brevidade para evitar 
maior esvaziamento no meio rural. A lógica de uso desta ferramenta GUT tem uma relação ou correlação das ações a serem atendidas diante de sua importância e consequente as demais.

Tal constatação pode ser comprovada pelas mais variados usos e aplicação para estabelecimento de prioridades e ordem de importância de ações a serem efetivadas, como constam em trabalhos, como de Faveri e Silva (2016), que pesquisaram a possibilidade de uso do Método GUT como mecanismo de auxílio na análise e hierarquização de risco de desastres, ou no trabalho de Pestana, Veras, Ferreira e Silva (2016), que buscaram analisar e propor melhorias processuais e organizacionais sob a luz de ferramentas organizacionais e da qualidade, matriz GUT e QFD (matriz da qualidade), a uma empresa de consultoria ambiental, e também como utilizar a Matriz GUT como planejamento estratégico organizacional, conforme a pesquisa de Alves, Mendonça, Medeiros e Magalhães (2018), o que demonstra a versatilidade de aplicabilidade de tal ferramenta.

A implantação e/ou incentivo de implantar e proporcionar condições favoráveis as agroindústrias nos municípios, potencializa a manutenção da população no meio rural, em seus empreendimentos agropecuários proporcionando maior rentabilidade com as agroindústrias, pois podem agregar valor aos produtos, ter maior realização por seus trabalhos, rentabilidade entre outros benefícios.

A faixa etária dos titulares das agroindústrias merece atenção, pois está num patamar que pode ser considerada elevada, e mais, não há registros de jovens em atividade nas agroindústrias, que por si só permite deduzir, que não haverá continuidade das mesmas, por não ter descendentes na atividade, mesmo com a contratação de mão de obra terceirizada, a qual também está cada vez mais escassa e com elevado custo. Essa consideração pertinente ao $3^{\circ}$ colocado, merece atenção, por deve ser motivado a iniciativa de jovens na atividade, por meio de processos mecanizados, tecnificados e informatizados, proporcionando um incentivo e estímulo para a agroindústria, com meios de gestão e condução das atividades com eloquência para melhor produtividade e satisfação aos mesmos.

A renda da agroindústria, ou melhor, obter maior rentabilidade dos agronegócios, além de considerar os itens anteriores, como $4^{\circ}$ item considerado, podem ser galgados com uma planificação das atividades, um adequado planejamento e estudo prévio de viabilidade de cada cultura a ser plantada ou produto a ser produzido, com estudos de potencialidade de mercados e custos bem como demais que se fazem necessários numa boa gestão. 
O tempo dedicado a agroindústria, sendo o $5^{\circ}$ item em ordem de valoração, pode estar atrelada a importância dela aos agroindustriais, diante das inúmeras oportunidades de mercado existentes, os produtos de origem direta de seus produtores podem ter um diferencial competitivo, consequentemente, demanda mais tempo em todos processos de programação de implantação das culturas para seu posterior processamento agroindustrial. Os produtos mais elaborados agregam mais valor e consequentemente são percebidos pelos consumidores, e geram uma confiabilidade e preferência pelos produtos de determinada agroindústria. Assim, o tempo e seu bom uso do tempo voltado as atividades agroindustriais, são de considerável valia.

A caracterização do município (população rural) necessita de incentivos e viabilidade de seus afazeres em seus empreendimentos agropecuários, os quais geralmente são módulos rurais menores que as culturas tradicionais que produzidas em escalas maiores e assim, não são compatíveis e viáveis em rentabilidade pelo dimensionamento das propriedades. Ou seja, pequenos módulos rurais, não comportam ter equipamentos para a devida mecanização, e a contratação e serviços terceirizados, ou fora de época se tornam inviáveis pela baixa produção auferida, o que demonstra que o caminho consiste em produzir produtos diferenciados e que possam agregar mais valor, proporcionando estabilidade ao empreendimento.

\section{Considerações Finais}

O Oeste do Paraná, com predominância de população urbana, faz parte do processo de transição para a estabilização e possível agregação de maior povoamento em áreas rurais. Para galgar resultados neste sentido, inúmeros procedimentos devem ser atendidos, por políticas públicas dos governos, pela iniciativa e criatividade dos próprios homens do campo em seus empreendimentos agropecuários e de atenção do mercado em valoração aos produtos, oriundos de agroindústrias para seu bem-estar.

A população rural, diminuindo por inúmeros fatores, baixa rentabilidade em pequenos módulos rurais, limitação a mecanização e as técnicas aprimoradas de cultivo e tratos culturais desencadeando em produtividades menores levam aos que persistem em suas atividades não tradicionais de cultivo, como os empreendimentos agropecuários voltados a agroindustrialização a buscarem formas de permanecer em suas propriedades, como 
registradas neste trabalho, mas com limitações e dificuldades em expandir ou auferir melhores conquistas e resultados financeiros para a estabilidade da atividade e de suas famílias.

Os ganhos de produtividade e rendimento nos empreendimentos agropecuários não acompanham em suas infraestruturas e aprimoramento de maquinários e equipamentos e técnicas de cultivo mais aprimoradas, sendo executadas muitas atividades com força humana, inibindo interesse e/ou proporcionando maiores custos aos salários nas agricultura, que podem tornar as agroindústrias insustentáveis.

O aprimoramento de máquinas e equipamentos para desempenhar as atividades com maior ganho de produtividade e menos esforço, uso de técnicas na implantaçao e condução das culturas, com assistência técnica, e locais para armazenagem e posterior distribuição dos produtos aos compradores se fazem imprencíndiveis num processo de gestão e de obtenção e resultados positivos. As maneiras de obter tais encaminhamentos que devem ser atendidos pela municipalidade diante do interesse dos empreendedores agropecuários, e/ou a junção dos mesmos em associações ou cooperativas, viabilizado a aquisiçao de maquinários ou equipamento que podem ser de uso comum, são alternativas para as agroindústrias.

A demanda por produtos naturais em ascensão permite horizontes de grande potencialidade, mas para tal, o planejamento e apropriação de procedimentos e técnicas consistem em ferramentas que os agroindustriais não podem desconsiderar.

A vocação agropecuária destes municípios considerados, deve permear o foco de investimentos a esses empreendimentos agropecuários de menor porte, pois eles são a grande força diferenciadora de produção e de estabilidade aos munícipes diante de sua estrutura produtiva e das agroindústrias alocadas nestas localidades. Para tanto deverá buscar estratégias, investir em capacitação e formar alianças para assumir um papel inovador nos processos produtivos familiares.

\section{REFERÊNCIAS}

ALVES, J.C.M. MENDONÇA, F.M. VELOSO, L.H.M. MAGALHÃES, G.H. Planejamento estratégico organizacional: reflexões a partir da utilização das matrizes SWOT e GUT em uma associação de catadores de materiais recicláveis. Sistemas \& Gestão 13 (2018), pp 219-231

ARAÚJO, M. J. Fundamentos de agronegócios. São Paulo: Atlas, 2005. 
BERDEGUE, J. Década da agricultura familiar: Carta aberta de Julio Berdegue, Representante Regional da FAO. Disponível em: http://www.fao.org/brasil/noticias/detailevents/en/c/1206221/. Acesso em 29 mar 2020.

BREITENBACH, R.; BÜNDCHEN, A.; BRANDÃO, J. B.; CAIRES, L. M. Perception of performance and importance to consumers agro-industry of family companies in the northern region of Rio Grande do Sul state. Ciência Rural, v. 47, n. 5, p. 1-7, 2017.

CAMARANO, A.A. ABRAMOVAY, R. Êxodo rural, envelhecimento e masculinização no Brasil: panorama dos últimos 50 anos. IPEA, Rio de Janeiro, 1999.

EMBRAPA. Visão 2030: o futuro da agricultura brasileira. - Brasília, DF: Embrapa, 2018.

FAO - Organização das Nações Unidas para Alimentação e Agricultura. Disponível em: http://www.fao.org/news/archive/news-by-date/2019/en/. Acesso em 30 mar 2020.

FAVERI, R. SILVA, A. Método GUT aplicado à gestão de risco de desastres: uma ferramenta de auxílio para hierarquização de riscos. Revista Ordem Pública. v. 9, n. 1, jan./jun., 2016

FOGUESATTO, C. R.; MACHADO, J. A. D. O processo decisório na criação de unidades que agregam valor à produção agropecuária: as agroindústrias familiares. Desenvolvimento em Questão, v. 15, n. 39, p. 301-319, 2017 a

GIL, A. C. Métodos e Técnicas de Pesquisa Social, 7. ed. Atlas, 03/2019.

IBGE: INSTITUTO BRASILEIRO DE GEOGRAFIA E ESTATÍSTICA. Censo

Populacional. 2010. Disponível em: https://censo2010.ibge.gov.br/. Acesso em 12 fev 2020.

Estimativas da População. 2019. Disponível em:

https://www.ibge.gov.br/estatisticas/sociais/populacao/9103-estimativas-depopulacao.html. Acesso em mar 2020.

/SIS. Síntese dos Indicadores Sociais 2002. IBGE, Coordenação de População e Indicadores Sociais. IBGE, Rio de Janeiro, 2002.

/SIS. Síntese dos Indicadores Sociais 2003. IBGE, Coordenação de População e Indicadores Sociais. IBGE, Rio de Janeiro, 2003.

Censo agropecuário: resultados definitivos / IBGE 2017. Disponível em: https:// biblio teca.ibge.gov.br/visualizacao/periodicos/3096/agro_2017_resultados_definitivos.pdf. Acesso em 02 abril 2020.

Censo Demográfico 2000. Disponível em: https://biblioteca.ibge.gov.br/ visualizacao/periodicos/88/cd_2000_migracao_deslocamento_amostra.pdf. Acesso em 26 $\underline{\operatorname{mar} 2020 .}$ 
IPARDES, Instituto Paranaense de Desenvolvimento Econômico e Social. Perfil Avançado dos Municípios. 2019a. Disponível em:

http://www.ipardes.gov.br/index.php?pg_conteudo=1\&cod_conteudo=29 Acesso em 13 nov 2019a.

Caderno Estatístico do município de Céu Azul, 2019b. Disponível em: http://www .ipardes.gov.br/cadernos/Monta CadPdf1.php?Municipio=85988\&btOk=ok. Acesso em 15 mai 2019b.

Caderno Estatístico do município de Entre Rios do Oeste, 2019c. Disponível em: http://www.ipardes.gov.br/cadernos/MontaCadPdf1.php?Municipio=85988\&btOk=ok. Acesso em 15 mai 2019c.

Caderno Estatístico do município de Guaíra, 2019d. Disponível em: http://www .ipardes.gov.br/cadernos/MontaCadPdf1.php?Municipio=85988\&btOk=ok. Acesso em 15 mai 2019d.

Caderno Estatístico do município de Matelândia, 2019e. Disponível em: http://www .ipardes.gov.br/cadernos/MontaCadPdf1.php?Municipio=85988\&btOk=ok. Acesso em 15 mai 2019e.

Caderno Estatístico do município de Medianeira, 2019f. Disponível em: http://www .ipardes.gov.br/cadernos/MontaCadPdf1.php?Municipio=85988\&btOk=ok. Acesso em 15 mai $2019 f$.

Caderno Estatístico do município de Pato Bragado, 2019g. Disponível em: http://www .ipardes.gov.br/cadernos/MontaCadPdf1.php?Municipio=85988\&btOk=ok. Acesso em 15 mai 2019g.

Caderno Estatístico do município de São Pedro do Iguaçu, 2019h. Disponível em: http://www .ipardes.gov.br/cadernos/MontaCadPdf1.php?Municipio=85988\&btOk=ok. Acesso em 15 mai 2019h.

Caderno Estatístico do município de Vera Cruz do Oeste, 2019i. Disponível em: http://www .ipardes.gov.br/cadernos/MontaCadPdf1.php?Municipio=85988\&btOk=ok. Acesso em 15 mai 2019i.

JACINTO, J.M. MENDES, C.M. PEREHOSUKEI, N.A. O rural e o urbano: contribuições para a compreensão da relação do espaço rural e do espaço urbano. Revista Percurso NEMO Maringá, v. 4, n. 2 , p. 173- 191, 2012.

KAGEYAMA, A. Diversificação das rendas nos domicílios agrícolas no Brasil, 1992 e 2001. Economia e Sociedade, v. 12, n. 1, p. 65-86, 2003.

KEPNER, C. H. TREGOE, B.B. The rational manager. New York, McGraw-Hill, 1965.

O administrador racional. São Paulo: Atlas, 1981. 
KOTLER, Philip; ARMSTRONG, Gary. Princípios de marketing. 9. ed. Prentice Hall, São Paulo, 2003.

MARICATO, E. Brasil, cidades: uma alternativa para a crise urbana. Petrópolis, Vozes, 2001.

MARTINS, G.A, THEÓPHILO, C.R Metodologia da Investigação Científica para Ciências Sociais Aplicadas, 3. ed. Atlas, 2016.

MARQUES, Z.S. Os intelectuais "contemporâneos" e o debate atual sobre o êxodo rural no brasil: uma abordagem sociológica. Trabalho de conclusão de curso (graduação) - Universidade Federal da Fronteira Sul, Curso de Licenciatura em Ciências Sociais, Erechim, RS, 2014.

MIOR, L. C. Agricultores familiares, agroindústrias e redes de desenvolvimento rural. Chapecó: Argos. 2005.

MOTA, L. T. História do Paraná: ocupação e relações interculturais. Maringá: EDUEM, 2005.

NITAHARA, A. Censo Agropecuário: Brasil tem 5 milhões de estabelecimentos rurais. Disponível em: https://agenciabrasil.ebc.com.br/geral/noticia/2019-10/censo-agropecuariobrasil-tem-5-milhoes-de-estabelecimentos-rurais. Acesso em 28 mar 2020.

PERIARD, Gustavo. Matriz GUT: Guia Completo, 2011. Disponível em: http://www.sobreadministracao.com/matriz-gut-guia-completo/ Acesso em: 23 fev. 2020.

PESTANA, M.D. VERAS, G.P. FERREIRA, M.T.M. SILVA, A.R. Aplicação integrada da matriz GUT e da matriz da qualidade em uma empresa de consultoria ambiental. um estudo de caso para elaboração de propostas de melhorias. XXXVI ENCONTRO NACIONAL DE ENGENHARIA DE PRODUCÃO. Contribuições da Engenharia de Produção para Melhores Práticas de Gestão e Modernização do Brasil João Pessoa/PB, Brasil, de 03 a 06 de outubro de 2016

PREZOTTO, L. L. Uma concepção da agroindústria rural de pequeno porte. Revista de Ciências Humanas, n. 31, 2002. p. 133-153.

PRIORI, A. POMARI, L.R. AMÂNCIO, S.M. IPÓLITO, V.K. História do Paraná: séculos XIX e XX. Maringá: Eduem, 2012. 234 p.

QUADROS, W. \& MAIA, A. G. Estrutura sócio-ocupacional no Brasil. Revista de Economia Contemporânea, 14(3), 2010. pp. 443-468.

SCHINAIDER, A.D.; BEZERRA, G.J. SANTOS JUNIOR, L.E., ATIYEL, C. CAPISTRANO, M.O.W. Agroindústria: conceitos e relação com o desenvolvimento rural, gestão e planejamento de agroindústrias familiares [recurso eletrônico] / organizadoras Daniela Garcez Wives [e] Daniela Dias Kühn; coordenado pela SEAD/UFRGS. - Dados eletrônicos. - Porto Alegre: Editora da UFRGS, 2018. 
SCHNEIDER, S. Teoria Social, agricultura familiar e pluriatividade. Revista Brasileira de Ciências Sociais, v. 18, n. 51, p. 99-121, 2003.

STECA, L. C.; FLORES, M. D. História do Paraná do século XVI à década de 1950. Londrina: Eduel, 2008.

TELLES, T.S.; COSTA, G.V.; CASTRO, G. H. L.; BACCHIM.D.; LAURENTI, A.C. Queda no número de empreendimentos agrícolas do Estado do Paraná, Brasil. Semina: Ciências Agrárias, Londrina, v. 40, n. 1, p. 127-138, jan./fev. 2019.

WACHOWICZ, R. C. História do Paraná. 10. ed. Curitiba: Vicentina, 2002.

WESZ JR. V.J.; TRENTIN I.C.L. FILIPPI, E. E. Os reflexos das agroindústrias familiares para o desenvolvimento das áreas rurais no Brasil. IV Congreso Internacional de La RED SIAL. Argentina, Mar Del Plata, 27 a 31 de outubro de 2008.

WESZ JUNIOR, V. J. Agroindústria familiar: um mecanismo de estímulo à especialização das atividades na propriedade rural? Mundo Agrário, v. 9, n. 18, 2009. 